\title{
Effect of prophylactic preoperative nursing interventions on prevention of endometritis among women undergoing elective caesarean delivery
}

\author{
Nahed Fikry Hassan Khedr, Eman A. Fadel * \\ Woman's Health and Midwifery Nursing Department, Faculty of Nursing, Mansoura University, Mansoura, Egypt
}

Received: July 13, 2016

DOI: $10.5430 /$ jnep.v6n12p142
Accepted: September 22, $2016 \quad$ Online Published: October 20, 2016

URL: http://dx.doi.org/10.5430/jnep.v6n12p142

\begin{abstract}
Objective: The single most important risk factor for postpartum endometritis is cesarean delivery. Aim: This study aimed to evaluate the effect of prophylactic preoperative nursing interventions on prevention of endometritis among women undergoing elective caesarean delivery.

Methods: Setting: This study was conducted in Operating Rooms, Postnatal Wards and Clinics of the Obstetrics and Gynecology Department at Mansoura University Hospital. Study Design: A randomized controlled clinical trial was utilized. Sample: A purposive sample of 150 parturient women undergoing elective cesarean section were randomly chosen according to inclusion criteria and then divided into three equal groups of 50 parturient women. Group one the control group received routine preoperative abdominal and thigh scrub with $10 \%$ Povidone Iodine and taken standard antibiotic regiment. There were two intervention groups; Group two participants received vaginal washing with $0.9 \%$ saline solution and group three participants received vaginal washing with $10 \%$ Povidone-iodine solution in addition to routine preoperative care.

Results: The findings of this study revealed that the risk of developing post-elective caesarean delivery endometritis was significantly lower in the intervention groups compared to the control group $(P<.05)$.

Conclusions: Vaginal washing with Povidone-iodine or saline solution immediately prior cesarean delivery significantly reduces the rate of post-elective caesarean delivery endometritis. Recommendation: Vaginal washing immediately prior to cesarean delivery should be a routine care to reduce the risk of postpartum endometritis.
\end{abstract}

Key Words: Elective caesarean delivery, Endometritis, Antiseptic solution, Saline, Nursing interventions

\section{INTRODUCTION}

Caesarean section (CS) defined as a surgical procedure in which delivery is performed through an incision of the abdomen and the uterus. CS continues to be the surgery most often performed in obstetric. ${ }^{[1]}$ Even though the rate of CS varies from one country to another the overall rate continues to rise from 5\% to 35\%. ${ }^{[2]}$ Despite the WHO recommenda- tion that CS rate should not exceed $10 \%-15 \%$ of all deliveries, the rate in USA reaches $32.9 \%,{ }^{[3,4]}$ while in Egypt it reaches $52 \%$ and $65.5 \%$, in Dakahlia. ${ }^{[5]}$ CS save lives of plenty of women and babies but when it performed without medical need, CS can lead to maternal morbidity. ${ }^{[6]}$

The most common maternal morbidity arising from CS is infection. ${ }^{[7]}$ In fact, cesarean delivery is the most significant

\footnotetext{
*Correspondence: Eman A. Fadel; Email: emy155_2005@hotmail.com; Address: Woman's Health and Midwifery Department, Faculty of Nursing, Mansoura University, Egypt.
} 
risk factor for postpartum infection. ${ }^{[8]}$ Postpartum infection has been shown to be eight-folds higher after surgical delivery than after normal delivery. ${ }^{[9]}$

The most common post CS maternal infectious morbidity involve any febrile morbidity resulting from a surgical site infection (SSI), endometritis or sepsis. ${ }^{[10]}$

Postpartum febrile morbidity is defined as an oral temperature of more than or equal to 38.0 degrees Celsius on any two days of the first ten days after delivery, exclusive of the immediate twenty four hours. Post CS (SSI) is diagnosed if any of two of the following findings is present; purulent discharge from the wound, wound cellulitis (erythema and warmth at the margins of the wound, skin quite tender to the touch). ${ }^{[11]}$

Postpartum endometritis is a clinical condition which usually includes uterine fundal tenderness, prurulent lochia or fever requiring antibiotic therapy. Post-cesarean endometritis is a result of an invasion of vaginal and cervical bacteria into the upper genital tract that infects the uterus. ${ }^{[12]}$ Preoperative vaginal washing with an antiseptic solution or an antimicrobial agent is a routine prophylactic nursing intervention that had been performed before many gynecological procedures to prevent post-procedure infection, but it is not a standard care before CS. ${ }^{[13]}$ There is an evidence that pre-operative vaginal washing before CS decrease the invasion of vaginal bacteria and microorganisms. ${ }^{[14]}$

There are many strategies to reduce post CS endometritis such as preoperative abdominal scrub, the use of antibiotics, washing the vagina with antiseptic solutions as well as the antiseptic technique during CS. ${ }^{[15]}$ Studies have shown that vaginal washing with povidone-iodine (PI) before obstetric surgery, such as CS, reduces postoperative infections however it may be an irritant to the skin. Other studies suggest vaginal washing with normal saline solution, which is used as an intravenous isotonic infusion and as a wound cleanser, and is effective in cleaning normal tissue without harm, unlike many stronger antiseptics. It is a readily available and an inexpensive agent in comparison to povidone iodine. ${ }^{[13]}$ Therefore, this study was employed to evaluate the effect of prophylactic preoperative nursing interventions (vaginal washing with $0.9 \%$ saline solution or vaginal washing with $10 \%$ povidone iodine) on the prevention of endometritis among women undergoing elective caesarean delivery.

\subsection{Significance of the study}

Post cesarean delivery endometritis has an alarming impact on the postpartum woman resumption to normal functioning and provision of newborn care. Despite the routine use of prophylactic antibiotics, there are one in 10 women may de-

Published by Sciedu Press velop post CS infectious morbidity resulting in a prolonged hospital stay that increases the cost for both the affected woman and the health care system. ${ }^{[16]}$

\subsection{Aim of this study}

This study aimed to evaluate the effect of prophylactic preoperative nursing interventions (vaginal washing with $0.9 \%$ saline solution or with $10 \%$ Povidone iodine) on prevention of endometritis among women undergoing elective caesarean delivery.

\subsection{Hypothesis}

Applying of prophylactic pre-operative nursing interventions (vaginal washing with $0.9 \%$ saline solution or with $10 \%$ Povidone iodine) will be effective than routine preoperative care on prevention of endometritis among women undergoing elective caesarean delivery.

\section{SUBJECTS AND METHODS}

\subsection{Study design}

A randomized controlled trial was utilized.

\subsection{Study setting}

This study was conducted in Operating Rooms, Postnatal Wards and Clinics of the Obstetrics and Gynecology Department at Mansoura University Hospitals.

\subsection{Sampling}

A purposive sample of one hundred and fifty parturient women undergoing to operating room to perform elective cesarean section and being at low-risk for postpartum infections during the period from September 2015 to March 2016.

\subsection{Sample size}

A previously performed study (Guzman et al., 2002) found that post-cesarean endometritis reduced for parturient women who were vaginally prepared with povidone-iodine or saline solution prior to cesarean delivery $(P<.04)$. On the basis of these data, to keep a specific margin of error of $5 \%$ with a confidence level of $95 \%$, approximately a total number of 147 parturient women needed for this study. Since the women were divided into three groups the number was 150 women, 50 in each group; the control group (Group one) received the routine preoperative abdominal and thigh scrub with $10 \%$ PI and taken standard antibiotic regiment; the intervention groups which include vaginal washing with $0.9 \%$ saline solution group (Group two) and vaginal washing with $10 \%$ PI solution group (Group three) also the intervention groups received the routine preoperative care. 


\subsection{Randomization}

Researchers obtained informed consent from all eligible women and provided adequate information about the trial. Eligible subjects were randomly assigned into three groups. Randomization was carried out using a numbered patient' name list. Even numbers recruited to the control group (Group one) and odd numbers recruited to the intervention groups starting with vaginal washing with saline solution group (Group two) until be completed then complete the vaginal washing with PI group (Group three).

\subsection{Inclusion criteria}

Women were chosen according to the following criteria:

- Women aged 20-40 years

- Primipara

- Single fetus

- Undergoing for elective cesarean section

- Healthy women free from any medical, infectious, obstetrical and gynecological diseases

\subsection{Exclusion criteria}

- Povidone-iodine hypersensitivity

- Emergency caesarean

\subsection{Tools of data collection: Two tools were used in data collection}

\section{Tool I. Structured interviewing questionnaire}

Was developed and filled by the researcher at first interview with the parturient woman at the operating room. It consists of two parts; the first part describes socio-demographic characteristics, medical, infectious, surgical, obstetrical and gynecological history. While the second part includes temperature record, state of the wound and length of hospital stay.

\section{Tool II. Follow up sheet (checklist)}

This tool was developed and filled by the researcher on the 7th day postpartum (first follow-up) and secondly on the second week (the second follow-up) postpartum. It includes the following items: 1) Wounds condition; 2) Signs and symptoms of postpartum endometritis such as (fever, uterine fundal tenderness, or purulent lochia).

\section{Tools validity}

Tools submitted to 3 experts in the field of maternity nursing and obstetrics medicine to test the content validity and the considered modifications were carried out by rephrasing of some sentences according to the experts' judgment on clarity of sentences and appropriateness of the content.

\subsection{Ethical considerations of the study}

Ethical approval and official permission were obtained from Research Ethics Committee, Faculty of Nursing, and Mansoura University. The researchers introduced themselves to the participants who met the inclusion criteria and an informed consent was obtained from them after explaining the purpose of the study. The participants were reassured about the confidentiality of the obtained information and were knowledgeable that the participation is voluntary and they can withdraw from the study at any time.

\subsection{Pilot study phase}

The pilot study was carried out on 15 parturient women; 5 from each group and they were excluded from the total sample. It was done to evaluate the clarity and applicability of the tools of data collection.

\subsection{Field of work}

I. At the waiting room for the operation: Participants' consent and history were obtained and initial assessment was performed.

II. At the operating room: After randomization all groups put on dorsal recumbent position and received routine abdominal and thigh scrub with $10 \%$ Povidone iodine and administered standard antibiotic regiment.

- The control group did not receive any vaginal washing just the routine preoperative care (abdominal and thigh scrub with $10 \%$ Povidone Iodine and administered standard antibiotic regiment).

- The intervention groups received vaginal washing for 30 seconds by using gauze soaked in $10 \%$ Povidoneiodine solution or in $0.9 \%$ saline solution by rotating movements $\left(360^{\circ} \mathrm{C}\right)$ from the upper part of vagina to the outlet.

III. At recovery room and postnatal ward: Postpartum care for the first 24 hours at the postpartum ward was the same for all groups; vital signs assessment each four hours, Foley catheter removal according to the policy of the department, signs of wound infection detection (swelling, discharge, erythema, or tenderness), lochia, and uterine involution assessment.

IV. Postnatal evaluation: Two postnatal follow-up visits were done; the first after one week and the second after two weeks postoperative for assessment of the following:

- Fever

- Endometritis

- Wound infection 


\subsection{Limitations of the study}

Lack of national and international studies related to the effect of saline on prevention of post cesarean section endometritis.

\subsection{Statistical analysis}

All statistical analyses were performed using SPSS for windows version 20.0 (SPSS, Chicago, IL). Continuous data were expressed as mean \pm standard deviation (SD), while categorical data were expressed in number and percentage. The differences between two groups or more were determined using independent samples student's $t$ test for variables with continuous data or chi-square test for variables containing categorical data. Statistical significance was set at $P<.05$.

\section{RESULTS}

Table 1 shows that the basic difference among the three groups as regards to age, gestational age and duration of operation were insignificant.

Table 1. Comparison of age, gestational age and operative duration among the control, saline solution and povidone-iodine solution groups

\begin{tabular}{|c|c|c|c|c|}
\hline \multirow{2}{*}{ Items } & \multirow{2}{*}{ Control Group } & \multicolumn{2}{|l|}{ Intervention Groups } & \multirow{2}{*}{$t$ test } \\
\hline & & Saline solution Group & Povidone-iodine solution Group & \\
\hline \multirow{2}{*}{ Age (years) } & \multirow{2}{*}{$29.0 \pm 5.4$} & \multirow{2}{*}{$27.2 \pm 4.9$} & \multirow{2}{*}{$28.8 \pm 5.1$} & $P 1=.084$ \\
\hline & & & & $P 3=.113$ \\
\hline \multirow{3}{*}{$\begin{array}{l}\text { Gestational age } \\
\text { (weeks) }\end{array}$} & \multirow{3}{*}{$36.9 \pm 2.5$} & \multirow{3}{*}{$36.7 \pm 2.1$} & \multirow{3}{*}{$36.5 \pm 2$} & $P 1=.666$ \\
\hline & & & & $P 2=.379$ \\
\hline & & & & $P 3=.627$ \\
\hline \multirow{3}{*}{$\begin{array}{l}\text { Operative duration } \\
\text { (minutes) }\end{array}$} & \multirow{3}{*}{$34.6 \pm 8.4$} & \multirow{3}{*}{$32.9 \pm 11.5$} & \multirow{3}{*}{$30.9 \pm 11.5$} & $P 1=.401$ \\
\hline & & & & $P 2=.069$ \\
\hline & & & & $P 3=.387$ \\
\hline
\end{tabular}

P1: Comparison between the control group and the Saline solution group; P2: Comparison between the control group and the Povidone-Iodine solution group; P3: Comparison between the Saline solution group and the Povidone - Iodine solution group.

Table 2 demonstrates the post-cesarean operation outcomes fever and wound infection were significantly more frequent among the control and the intervention groups. After the first in the control group as compared to the saline solution group and the second postnatal follow-up, the rate of endometritis, and the povidone-iodine solution group $(P 1 \& P 2<.05)$.

Table 2. Comparison of post-cesarean outcomes among the control, saline solution and povidone-iodine solution groups

\begin{tabular}{|c|c|c|c|c|c|c|c|}
\hline \multirow{3}{*}{ Items } & \multirow{2}{*}{\multicolumn{2}{|c|}{ Control Group }} & \multicolumn{4}{|c|}{ Intervention Groups } & \multirow{3}{*}{$\begin{array}{l}\text { Chi square } \\
\text { test }\end{array}$} \\
\hline & & & \multicolumn{2}{|c|}{ Saline Solution Group } & \multicolumn{2}{|c|}{ Povidone-Iodine Solution Group } & \\
\hline & $\mathbf{n}$ & $\%$ & $\mathbf{n}$ & $\%$ & $\mathbf{n}$ & $\%$ & \\
\hline \multicolumn{8}{|c|}{ First postnatal follow-up } \\
\hline Endometritis & 8 & 16 & 1 & 2 & 2 & 4 & $\begin{array}{l}P 1=.014 \\
P 2=.046 \\
P 3=.557\end{array}$ \\
\hline Fever & 9 & 18 & 1 & 2 & 2 & 4 & $\begin{array}{l}P 1=.008 \\
P 2=.025 \\
P 3=.557\end{array}$ \\
\hline Wound infection & 7 & 14 & 0 & 0 & 1 & 2 & $\begin{array}{l}P 1=.006 \\
P 2=.027 \\
P 3=.315\end{array}$ \\
\hline \multicolumn{8}{|c|}{ Second postnatal follow-up } \\
\hline Endometritis & 7 & 14 & 0 & 0 & 1 & 2 & $\begin{array}{l}P 1=.006 \\
P 2=.027 \\
P 3=.315\end{array}$ \\
\hline Fever & 8 & 16 & 0 & 0 & 1 & 2 & $\begin{array}{l}P 1=.003 \\
P 2=.012 \\
P 3=.315\end{array}$ \\
\hline Wound infection & 7 & 14 & 0 & 0 & 0 & 0 & $\begin{array}{l}P 1=.006 \\
P 2=.006 \\
P 3=1.000\end{array}$ \\
\hline
\end{tabular}


As shown in Figure 1, the post-operative stay was signifi- done-iodine solution group $(4.7 \pm 2.4$ versus $2.6 \pm 1.1$ cantly longer in the control group than the saline solution group $(4.7 \pm 2.4$ versus $2.4 \pm 0.9$ days, $P 1<.001)$, and was significantly longer in the control group than the povidays, $P 2<.001)$ whereas the difference of length of hospital stays did not differ significantly between the two intervention groups.

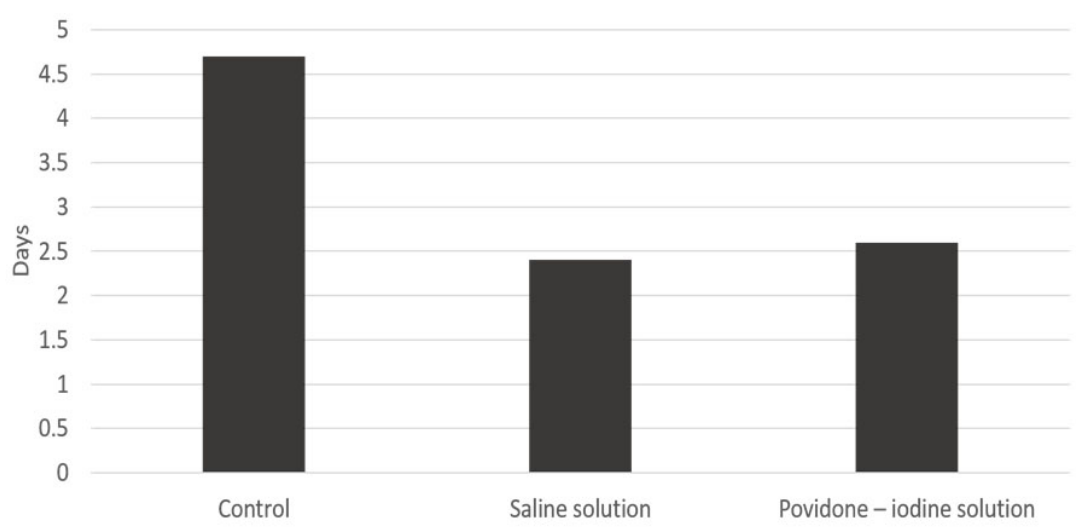

Figure 1. Comparison of length of hospital stay among the control, saline solution and povidone-iodine solution groups

\section{Discussion}

This study aimed to evaluate the effect of prophylactic preoperative nursing interventions (vaginal washing with $0.9 \%$ saline solution or with $10 \%$ Povidone iodine) on prevention of endometritis among women undergoing elective caesarean delivery. The aim was achieved through the present study findings which revealed that the intervention groups; Group (two) vaginal washing with $0.9 \%$ saline solution \& group (three) vaginal washing with $10 \%$ Povidone-iodine had statistically significantly differences in the prevention of post-elective caesarean delivery endometritis than the control group (Group one).

The study finding is supported by seven randomized trials involving 2,635 women conducted from 2005 to 2012 in Iran, Pakistan, Turkey and the USA. All trials compared preoperative vaginal washing with povidone-iodine solution with no vaginal washing in six trials and one trial with preoperative vaginal washing with saline solution. ${ }^{[7,16]}$ Such studies findings revealed that the incidence of post-caesarean endometritis significantly decreased in those subjects who scrubbed with both abdominal and vaginal with povidoneiodine, compared with those who received a standard abdominal scrub alone. Consistent with this finding a randomized controlled trial in USA on 160 parturient women with cesarean section were randomized to vaginal washing with either Povidone-Iodine $(n=80)$ or saline $(n=80)$. Such study result revealed that vaginal preparation before cesarean delivery significantly reduces the incidence of post-cesarean endometritis but not affects wound infection. ${ }^{[17]}$

Also another study carried out by Yildirim et al. ${ }^{[18]}$ supported the research finding by evaluating the effect of vaginal 146 preparation with povidone-iodine prior to caesarean delivery on the incidence of postpartum endometritis through a randomized controlled trial on 334 women with povidone-iodine vaginal cleansing and 336 women with no vaginal cleansing. The randomized controlled trial reported that vaginal preparation with povidone-iodine solution immediately prior to a caesarean delivery reduces the risk of post-operative endometritis.

Contradict, other studies had been done by Haas et al. and Reid et al. ${ }^{[19,20]}$ did not show any statistically significant difference in post caesarean fever, endometritis or wound infection. This contradiction due to the various risk factors for developing postpartum endometritis among women undergoing elective caesarean delivery such as the use of internal monitors, cervical dilatation at the time of caesarean section, prolonged labour, prolonged rupture of membranes and maternal sever anemia.

The study finding revealed that parturient women with elective cesarean section who expose to vaginal cleansing with $0.9 \%$ saline solution or with $10 \%$ Povidone-Iodine exhibit lesser postpartum infections than women in the control group. Parallel with this finding, many reports in the literature proved that the mechanical cleansing of the vagina, not only the use of an antiseptic solution, is responsible for the efficacy of vaginal preparations such as a recent report by Amstey et al. ${ }^{[21]}$ proved that, saline solution can be effective on the prevention of postoperative infections after vaginal surgery as effective as Povidone-Iodine. While other cohort study by Lewis et al. ${ }^{[22]}$ had been compared the postoperative infection rates between either povidone-iodine or diluted baby shampoo in normal saline vaginal cleansing before gyneco- 
logical surgery on 96 women with Povidone-iodine vaginal cleansing and 153 women with diluted baby shampoo in normal saline vaginal cleansing. The cohort study proved that the Baby shampoo which is diluted in $0.9 \%$ normal saline solution is preferable than $10 \%$ Povidone-Iodine in vaginal cleansing before gynecological procedures because it has minimal vaginal irritation and is cheaper than PovidoneIodine.

Consistent with this finding, other researches ${ }^{[23]}$ had been conducted in Swedish to evaluate whether pre-opertaive vaginal cleansing reduces the risk of postoperative infection after abdominal total hysterectomy or not; They revealed that vaginal cleansing with chlorhexidine solution did not reduce the risk of postoperative infections, whereas vaginal cleansing with saline solution reduces the risk for postoperative infectious morbidity. Saline solution is used as an intravenous isotonic infusion and for cleaning wounds. It is a mild but an effective cleaning agent and don't harm normal tissue, unlike many stronger antiseptics. It is available, non-irritant, not causing vaginal mucosal coloration and inexpensive in comparison to Povidone-Iodine.

The study finding indicates that the postoperative hospital length of stay for the control group differ significantly than the intervention groups. But this result is inconsistent with other researchers in Egypt ${ }^{[24]}$ who had evaluated the effect of cleansing birth canal pre-normal delivery with an antiseptic solution on the occurrence of maternal and newborn infections; they revealed that there is no statistical significant difference between the control and intervention groups on the hospital stays. This contradiction is due to the difference in the hospital stays between normal and cesarean section deliveries.

\section{Conclusion}

Vaginal washing with Povidone-iodine or saline solutions immediately prior cesarean section significantly reduces the rate of postoperative endometritis, fever and wound infection.

\section{RECOMMENDATION}

(1) Future study about the effect of vulval washing with normal saline solution on prevention of post-elective cesarean delivery endometritis.

(2) Vaginal washing immediately prior cesarean delivery should be a routine care to reduce the risk of postpartum endometritis.

(3) Saline solution should be used as an alternative to Povidone- iodine for vaginal cleansing because it is a non-irritant, an inexpensive and a mild detergent.

\section{OPERATIONAL DEFINITION}

(1) Prophylactic nursing interventions: Are vaginal washing with saline solution or vaginal washing with Povidone-iodine solution in addition to routine preoperative abdominal and thigh scrub and administration of standard antibiotic regiment.

(2) Elective cesarean section: Is a planned first cesarean section in a healthy woman for giving birth of a baby without medical or obstetric indications for the surgery.

(3) Postpartum endometritis: Is defined as a clinical diagnosis, usually involving uterine fundal tenderness, fever, purulent lochia, requiring antibiotic regiment.

(4) Postoperative wound infection: Is the appearance of erythema, with or without fever tenderness, or purulent discharge in the incision site, requiring treatment with an antibiotic regiment.

(5) Postoperative fever (pyrexia): Is defined as an oral temperature more than $38^{\circ} \mathrm{C}$ or $100.4^{\circ} \mathrm{F}$.

\section{CONFLicts OF INTEREST Disclosure}

The authors declare that there is no conflict of interest.

\section{REFERENCES}

[1] Kaur S, Sikka P. A quasi-experimental study to assess the effectiveness of early ambulation in post-operative recovery among postcaesarean mothers admitted in selected areas of Nehru Hospital. Chandigarh. Nursing and Midwifery Research Journal. 2015.

[2] Vogel J, Betran A, Vindevoghel N, et al. Use of the Robson classification to assess caesarean section trends in 21 countries: a secondary analysis of two WHO multicountry surveys on behalf of the WHO Multi-Country Survey on Maternal and Newborn Health Research Network. Lancet Global Health. 2015; 3(5): e260-70. http://dx.doi.org/10.1016/S2214-109x (15) 70094-X

[3] WHO \& Geneva. WHO Statement on Caesarean Sections. Cae- sarean Sections should only be performed when medically necessary. News release. Accessed 20 April 2015. Available from: http://www.who.int/mediacentre/news/releases/ 2015/caesarean-sections/en/

[4] Joyce A, Martin MPH, Hamilton BE, et al. Births: Final Data for 2013, National Vital Statistics Reports. 2015.

[5] Zakerihamidi M, Latifnejad RR, Merghati KE. Vaginal delivery vs Caesarean Section: A focused Ethnographic. Study of Women Perceptions in the North of Iran. International Journal of Community Based Nursing and Midwifery. 2015; 3(1): 39-50.

[6] Gibbons L, José M, Belizán JA, et al. The Global Numbers and Costs of Additionally Needed and Unnecessary Caesarean Sections Per- 
formed per Year: Overuse as a Barrier to Universal Coverage. World Health Report. 2010.

[7] Asghania M, Mirblouk F, Shakiba M, et al. Preoperative vaginal preparation with povidone-iodine on post caesarean infectious morbidity. Journal of Obstetrics and Gynaecology. 2011; 31(5): 400403. PMid:21627422 http://dx.doi.org/10.3109/01443615. 2011.568644

[8] Tikkanen S, Button A, Zamba G, et al. Effect of chlorhexidine skin prep and subcuticular skin closureon post-operative infectious morbidity and wound complication Following cesarean section. Proceedings in Obstetrics and Gynecology. 2013; 3(2): 2.

[9] Shrestha S, Shrestha R, Shrestha B, et al. Incidence and Risk Factors of Surgical Site Infection Following Cesarean Section at Dhulikhel Hospital. Kathmandu University Medical Journal. 2014; 46(2): 1136.

[10] Conroy K, KoeningA, Yu Y, et al. Infectious Morbidity after Cesarean Delivery: 10 Strategies to Reduce Risk. Obstetrics \& Gynecology. 2012; 5(2): 69-77.

[11] Dyrkorn O, Kristoffersen M, Wellberg M. Reducing post-caesarean surgical wound infection rate: an improvement project in a Norwegian maternity clinic. BMJ Quality and Safety. 2012; 21(3): 206-210. PMid:22233981 http://dx.doi.org/10.1136/bmjqs-2011-0 00316

[12] Dhanya M, Roger E, Erika O, et al. Antibiotic regimens for postpartum endometritis, Cochrane Database of Systematic Reviews. 2015.

[13] Derbent A, Ulukanlıgil M, Keskin E, et al. Does Vaginal Irrigation with Saline Solution in Women with Infectious Vaginitis Contribute to the Clinical and Microbiological Results of Antibiotic Therapy? Gynecological and Obstetric Investigation, 2012; 73(3): 195-200. PMid:22301569 http://dx.doi .org/10.1159/000332396

[14] Abdallah A. Evaluation of the risk of post caesarean endometritis with preoperative vaginal preparation with povidone- iodine: A ranamized controlled study. Middle East Fertility Society Journal. 2015; 20(4): 246-250. http://dx.doi.org/10.1016/j.mefs . 2015.03.002

[15] Sekhavat L, Tabatabaii A. Intravaginal Metronidazole for the Prevention of Postcesarean Endometritis. Journal of Isfahan Medical School. 2009; 27(92): 30-35.

[16] Haas DM, Morgan Al Darei S, Contreras K.Vaginal Preparation With Antiseptic Solution Before Cesarean Section For Preventing Postop- erative infections Cochrane Database of Systematic Reviews. 2014; 17(3). PMid:25203198 http://dx.doi.org/10.1002/1465185 8. CD007892 . pub4

[17] Guzman M, Prien S, Blann D. Post-cesarean related infection and vaginal preparation with povidone-iodine revisited. Primary Care Update for Obstetric/GYNS. 2002; 9(6): 206-209. http: //dx. doi . org/10.1016/S1068-607X (02) 00119-1

[18] Yildirim G, Güngördük K, Asicioğlu $\mathrm{O}$, et al. Does vaginal preparation with povidone-iodine prior to caesarean delivery reduce the risk of endometritis? A randomized controlled trial. Journal Maternal Fetal Neonatal Medical. 2012; 25(11): 2316-21. PMid:22590998 http://dx.doi.org/10.3109/14767058.2012.693994

[19] Haas DM, Pazouki F, Smith RR, et al. Vaginal cleansing before cesarean delivery to reduce postoperative infectious morbidity: a randomized, controlled trial. American Journal of Obstetrics \& Gynecology. 2010; 202(3): 310.e1-6. PMid:20207251 http://dx.d oi.org/10.1016/j.ajog.2010.01.005

[20] Reid VC, Hartmann KE, McMahon M, et al. Vaginal preparation with Povidone-iodine and postcesearen section infectious morbidity: a randomized controlled trial. Obsetetric and Gynecology. 2001; 97: 147-52. PMid:11152924

[21] Amstey, et al. Povidone-iodine Versus Normal Saline Solution in Vaginal Cleansing in Laparoscopy. ClinicalTrials.gov processed this data on October 29, 2015. Available from: http://clinicaltria ls.gov/show/NCT02591251

[22] Lewis LA, Lathi RB, Crochet P, et al. Preoperative vaginal preparation with baby shampoo compared with povidone-iodine before gynecologic procedures. Journal of Minimmaly Invasive Gynecology. 2007; 14(6): 736-9. PMid:17980335 http://dx.doi.org/10.10 $16 / j \cdot j$ mig. 2007.05.010

[23] Kjølhede P, Halili S, Löfgren M. The influence of preoperative vaginal cleansing on postoperative infectious morbidity in abdominal total hysterectomy for benign indications. Acta Obstetetrica et Gynecologica Scandinavica. 2009; 88(4): 408-16. PMid:19235564 http://dx.doi.org/10.1080/00016340902795345

[24] Bakr A, Karkour T. Effect of Predelivery vaginal antisepsis on maternal and neonatal morbidity and mortality in Egypt. Journal of Women's Health. 2005; 14(6): 496-501. PMid:16115003 http://dx.doi.org/10.1089/jwh.2005.14.496 